\title{
Event-Based Surveillance During EXPO Milan 2015: Rationale, Tools, Procedures, and Initial Results
}

Flavia Riccardo, Martina Del Manso, Maria Grazia Caporali, Christian Napoli, Jens P. Linge, Eleonora Mantica, Marco Verile, Alessandra Piatti, Maria Grazia Pompa, Loredana Vellucci, Virgilio Costanzo, Anan Judina Bastiampillai, Eugenia Gabrielli, Maria Gramegna, Silvia Declich; and the Regional Focal Points for EBS Surveillance Work Group

More than 21 million participants attended EXPO Milan from May to October 2015, making it one of the largest protracted mass gathering events in Europe. Given the expected national and international population movement and health security issues associated with this event, Italy fully implemented, for the first time, an event-based surveillance (EBS) system focusing on naturally occurring infectious diseases and the monitoring of biological agents with potential for intentional release. The system started its pilot phase in March 2015 and was fully operational between April and November 2015. In order to set the specific objectives of the EBS system, and its complementary role to indicator-based surveillance, we defined a list of priority diseases and conditions. This list was designed on the basis of the probability and possible public health impact of infectious disease transmission, existing statutory surveillance systems in place, and any surveillance enhancements during the mass gathering event. This article reports the methodology used to design the EBS system for EXPO Milan and the results of 8 months of surveillance.

A MASS GATHERING EVENT has been defined by the World Health Organization (WHO) as a gathering of people at a specific location, for a specific purpose, and for a defined period of time. ${ }^{1}$ An international exposition, EXPO 2015, took place in the city of Milan (Lombardia, Italy) between

May 1 and October 31, 2015. ${ }^{2}$ A diverse population was expected to attend, including families and business groups. Short stays were expected for visitors and longer stays for staff members, both Italian and foreign. According to preliminary official data, more than 21 million visitors attended

Flavia Riccardo, PhD, and Martina Del Manso, who has a degree in statistics, are Researchers; Maria Grazia Caporali, who has a degree in biology, is a Technician; Silvia Declich, MSc, is Senior Epidemiologist and Head; and, at the time the article was written, Christian Napoli, MD, was a Researcher; all in the Communicable Disease Epidemiology Unit, National Centre for Epidemiology, Surveillance and Health Promotion, Istituto Superiore di Sanità (Italian National Institute of Health), Rome, Italy. Dr. Riccardo is also with the European Programme for Intervention Epidemiology Training (EPIET), European Centre for Disease Prevention and Control, (ECDC), Stockholm, Sweden. Jens P. Linge, PhD, is Scientific Officer, Global Security and Crisis Management Unit; Eleonora Mantica, MA, is Business Analyst; and Marco Verile, MS, is Scientific/Technical Project Officer; all at the European Commission, Joint Research Centre, Institute for the Protection and Security of the Citizen, Ispra, Varese, Italy. Alessandra Piatti, PhD, is a public health doctor, General Directorate of Health, Lombardy Region, Milan, Italy. Maria Grazia Pompa, MD, is Senior Medical Officer; Loredana Vellucci, MD, PhD, is Chief of the Office 3, Coordination of Port, Airport and Border Offices; and Virgilio Costanzo, MD, is Medical Officer; all at the Directorate General of Prevention, Italian Ministry of Health, Rome. Anan Judina Bastiampillai, MD, is a resident at the Hygiene and Preventive Medicine School of Milan. Eugenia Gabrielli, MD, is a resident in Hygiene and Public Health, Scuola di Specializzazione in Igiene e Medicina Preventiva, Università degli studi di Milano, Milan. Maria Gramegna, MD, is Director, Prevention Unit, DG Welfare, Lombardia Region, Milan, Italy.

(C) Flavia Riccardo, et al., 2016; Published by Mary Ann Liebert, Inc. This Open Access article is distributed under the terms of the Creative Commons Attribution Noncommercial License (http://creativecommons.org/licenses/by-nc/4.0/) which permits any noncommercial use, distribution, and reproduction in any medium, provided the original author(s) and the source are credited. 
this event, ${ }^{3}$ and 140 countries officially participated. The size and duration of EXPO 2015 made it one of the largest protracted mass gatherings in Europe. Its occurrence led to a number of initiatives aimed at encouraging tourism across Italy, ${ }^{4}$ including discounts for foreign visitors of Italian origin $^{5}$ and increased train connections to the EXPO venue. ${ }^{6,7}$ For this reason, during this mass gathering, high population mobility across Italy was expected.

Mass gatherings attended by a large number of people are known to strain the planning and response resources of hosting countries, ${ }^{1}$ are linked to an increased risk for infectious disease transmission, and are a potential target for the intentional release of biological agents. ${ }^{8}$ The risk of importation or exportation of infectious diseases following the arrival to and departure from the gathering venue also needed to be considered. ${ }^{1}$ Outbreaks caused by a wide variety of pathogens have consistently been linked to mass gatherings in the past. ${ }^{9-15}$

In order to boost preparedness for outbreak detection, the Italian health authorities set up an EXPO-tailored epidemic intelligence (EI) system. Epidemic intelligence has been defined by WHO as "the systematic collection, analysis and communication of any information to detect, verify, assess and investigate events and health risks with an early warning objective."16(p3) This process typically integrates indicator-based surveillance (IBS) and event-based surveillance (EBS) components.

Indicator-based surveillance in Italy is well established. It comprises legally regulated systems that collect and analyze case-based clinical data routinely collected from healthcare facilities (statutory surveillance) as well as sentinel syndromic surveillance systems that collect and analyze more timely aggregated data reporting syndromes rather than individual diseases. $^{17-23}$ During EXPO 2015, an existing emergency visit-based syndromic surveillance system, originally set up for the 2006 Turin Winter Olympic games, ${ }^{21}$ was enhanced by recruiting additional reporting units in the Lombardia region and increasing reporting from once to twice per week.

In contrast with indicator-based surveillance, eventbased surveillance is designed to capture information from real-time unstructured data and from sources, both within and beyond the health sector, that can be official or unofficial. $^{24,25}$ Because of their timeliness, internet-based media, blogs, and social networks are frequent sources for this type of surveillance. Therefore, the information collected is mostly unverified, not standardized, and needs to be assessed and validated before being used for public health purposes. Event-based surveillance in Italy is not a routine activity but has been piloted with various objectives and targets since $2010 .^{26}$

The EXPO 2015 gathering led Italian authorities to consider the need for an event-based surveillance system to identify:

- infectious diseases occurring in the Lombardia region and their possible links with EXPO 2015;
- infectious diseases occurring in the 21 Italian regions and autonomous provinces (hereafter regions) and their possible links with EXPO 2015;

- international outbreaks that could have an impact on EXPO 2015; and

- any infectious disease epidemiologically linked with EXPO 2015 occurring internationally.

Lombardia set up an EXPO epidemic intelligence team in Milan to address the first identified need. ${ }^{27}$ The European Centre for Disease Prevention and Control (ECDC) ${ }^{28}$ and the Early Alerting and Reporting Project of the Global Health Security Initiative (GHSAG EAR) ${ }^{25}$ agreed to insert EXPO among the topics for threat detection in their eventbased surveillance systems at European Union (EU) and global levels, respectively, thus addressing the third and fourth needs. The Disease Epidemiology Unit of the National Centre of Epidemiology Surveillance and Health Promotion (IDEU-CNESPS), Istituto Superiore di Sanità (ISS), agreed to set up an event-based surveillance system to monitor infectious diseases occurring in the 21 Italian regions and their possible links with EXPO 2015. In this article, we focus on the design and implementation of this event-based surveillance system and provide initial results ahead of a formal evaluation.

\section{Materials and Methods}

We defined the list of priority diseases, pathogens, and conditions for EXPO event-based surveillance on the basis of the risk of infectious disease transmission during the gathering. As a starting point, we used the list of diseases, pathogens, and conditions identified for event-based surveillance during the 2012 London Olympic and Paralympic Games. ${ }^{8}$ We chose this list for 3 reasons: first, because it was the result of a structured, extensive risk assessment and prioritization exercise that had involved a large number of subject matter experts; second, because the London Games had occurred recently; and third, because, like EXPO, the London Games had been a large mass gathering in Europe occurring mainly during summer months.

In order to take into account more recent potential public health emergencies of international concern (PHEIC), we included in the list the potential public health emergencies of international concern reported in the WHO Event Information Site (EIS) between 2014 and 2015. ${ }^{29}$ We also included any endemic or emerging disease in Italy that had not yet been considered, on the basis of the opinion of the national disease experts of the IDEUCNESPS ISS.

Each disease, pathogen, and condition we included in the list was assessed by the event-based surveillance analysts for the risk of the following 3 occurrences: (1) being imported to Italy, (2) causing outbreaks in the EXPO setting, and (3) being exported from Italy to other countries. We 
drafted a first assessment of the probability and impact of these 3 occurrences, on the basis of scientific literature and of the risk assessments published by ECDC and WHO. This assessment consisted of a descriptive paragraph for each disease, pathogen, and condition, quoting all referenced sources and of a qualitative 9-point scale of risk, scoring from very low to very high for each of the 3 mentioned occurrences.

We then shared our assessment with the IDEU-CNESPS disease experts, who provided input and validated the results using the following process. First, we invited all IDEU-CNESPS experts for the diseases, pathogens, and conditions assessed to be part of an expert panel for the assessment of the risk of infectious disease transmission during the EXPO gathering, and we shared with them the draft risk assessment report. Second, we individually interviewed each disease expert for the areas of his or her specific competence, explaining our findings and discussing the preliminary assessment. On this occasion, each expert reassessed the ranking of the probability and impact of each occurrence, adjusting or validating our proposal. Finally, the revised risk assessment report was recirculated to the expert panel, who approved the final version. On the basis of this ranking, we defined the final list of diseases, pathogens, and conditions to consider for the EXPO 2015 event-based surveillance.

To integrate event-based surveillance into the Italian surveillance context, we assessed whether the identified diseases, pathogens, and conditions were being monitored by indicator-based surveillance systems, both routinely present and enhanced during EXPO. On the basis of this analysis, we defined the specific objectives of the Italian national event-based surveillance: to capture information related to communicable diseases or to biological agents with potential for intentional release, occurring in Italy or linked to EXPO 2015.

\section{Event-Based Surveillance}

The Medical Information System (MedISys) is a fully automatic event-based surveillance platform that monitors reporting on infectious diseases in humans and animals; chemical, biological, radiological, and nuclear (CBRN) threats; plant health; and food and feed contaminations on the internet. ${ }^{30,31}$ The system retrieves news articles from specialized official and nonofficial medical sites, general news media, and selected blogs; categorizes all incoming articles according to predefined multilingual disease categories; identifies known names, such as organizations, people, and locations; extracts events; clusters news articles; and calculates statistics to detect emerging threats. Any internet user can screen the categorized articles and display world maps highlighting event locations together with statistics on the reporting of health threats, countries, and combinations thereof. Articles can be further filtered by language, news source, and country. Analysts working with the platform can also use a nonpublic collaborative tool called NewsDesk to select automatically retrieved articles and create and deliver reports and notifications via email or short message service (SMS). The MedISys platform has been used in the past to monitor infectious diseases of public health importance ${ }^{32-34}$ and during mass gatherings. ${ }^{35}$

Leading up to EXPO 2015, additional MedISys categories including various combinations of the key word patterns related to EXPO 2015 were created and combined using a Boolean filter with the disease categories of the diseases, pathogens, and conditions we had identified. We also increased the sensitivity of MedISys to events occurring within Italy by searching and adding 4,218 Italian internet sources. Of these, 3,831 were unofficial websites, including media and blogs, and 387 were official websites (of which 31 were national, 43 regional, and 313 at the health-unit/ municipality level). This work was particularly important because MedISys retrieves articles from a predetermined source directory. Therefore, if an item is published by a source not included in the MedISys source directory, it cannot be retrieved by MedISys. We complemented the monitoring of MedISys by monitoring Google Alerts designed to capture items in Italian on the diseases, pathogens, and conditions we had identified. The advantage of this approach was that Google Alerts do not retrieve articles from a predefined source directory but are based on the Google search engine technology. When analysts detected relevant items from Google Alerts that were not retrieved by MedISys, they sent the related sources via email to the MedISys developers at the Joint Research Centre (JRC), thereby constantly updating the MedISys source directory.

We defined an item as any text filtered by the MedISys platform or captured by our defined Google Alerts, a signal as any item containing information on cases of communicable diseases in Italy, and an event as any new signal with public health relevance.

Finally, in order to identify among all events those that had involved a larger number of human cases, we further defined "EBS priority events." Event-based surveillance priority events included all events describing more than 2 human cases of an infectious disease that presented an epidemiologic link (in time, place, and/or person) and all situations where more than 1 event reported human cases of an infectious disease that presented an epidemiologic link.

In order to help analysts in assessing the relevance of information in a consistent way, and therefore to identify when signals could qualify as events, we designed a set of 12 standardized unweighted questions that could be independently scored (Table 1). We included the following aspects: health impact, severity, spread, etiology, epidemiologic characteristics of the pathogen (such as endemicity, emergence, elimination targets, etc), clinical presentation, vulnerability of affected communities, European Early Warning and Response System (EWRS)/International Health Regulations (IHR) reporting eligibility, occurrence in international border areas, and reliability of the information source. We tested 
Table 1. Italian Event-Based Surveillance Assessment Tool

\begin{tabular}{|c|c|c|c|}
\hline$N$ & Question & Score & Comments \\
\hline & Public Health Impact & & \\
\hline 0 & Impact of the event on public health & $1-4$ & $\begin{array}{l}1 \text { - No impact (the event does not imply changes in public health } \\
\text { actions) } \\
2 \text { - Medium impact (the event stimulates nonurgent public health } \\
\text { actions and/or actions aimed at preventing nonsevere disease in } \\
\text { the population) } \\
3 \text { - High impact (the event stimulates urgent public health actions } \\
\text { and/or actions aimed at preventing severe disease in the } \\
\text { population) } \\
4 \text { - Very high impact (the event has a national and/or } \\
\text { international relevance-eg, autochthonous cases of new } \\
\text { diseases, first seasonal case of influenza) }\end{array}$ \\
\hline 1 & Severity (case fatality, severity of symptoms) & $1-3$ & $\begin{array}{l}1 \text { - Low impact (no case of disease or cases of mild disease) } \\
2 \text { - Medium impact (hospitalized cases) } \\
3 \text { - High impact (cases with severe disease, hospitalized in } \\
\text { intensive care units, and/or dead) }\end{array}$ \\
\hline$\overline{2}$ & Spread & $1-3$ & $\begin{array}{l}1 \text { - Localized event/spread unknown } \\
2 \text { - High number of cases in one region } \\
3 \text { - Cases in more than one region }\end{array}$ \\
\hline
\end{tabular}

\begin{tabular}{l} 
Epidemiology \\
\hline $\begin{array}{l}\text { Is the disease endemic? Is the event described } \\
\text { common in Italy? }\end{array}$
\end{tabular}

4 Is clinical presentation (including outcome and response to treatment or drug resistance) as expected?

5 Does the epidemiology (etiology and distribution) suggest an intentional release?

6 Is it a cluster of a disease targeted for elimination in Italy?

1-3 1 - Event describes an endemic disease in Italy, epidemiology as expected

2 - Epidemiology unusual but within accepted norms/unknown disease $^{a}$

3 - Unexpected or unusual event and/or disease nonendemic in Italy

1-3 1 - Clinical presentation as expected or unknown ${ }^{\mathrm{a}}$

2 - Atypical clinical presentation but compatible with a naturally occurring disease

3 - Very unusual clinical presentation

1-3 1 - Epidemiology as expected

2 - Epidemiology atypical but compatible with a naturally occurring disease

3 - Very unusual epidemiology, possible intentional release

1-3 $1-$ No/unknown ${ }^{\mathrm{a}}$

2 - Possibly

$3-$ Yes

\begin{tabular}{ccc}
\hline $7 \quad$ Is the event occurring in vulnerable communities (Roma/Sinti & $1-3$ & $1-$ No/unknown \\
communities, migrant populations, socio-economically vulnerable & $2-$ Possibly \\
communities, etc) and/or susceptible & $3-$ Yes
\end{tabular}

communities (schools, prisons, cruise ships, etc)?

\begin{tabular}{|c|c|c|c|}
\hline 8 & $\begin{array}{l}\text { Is the event describing an emerging disease, a re-emerging disease, or } \\
\text { a disease at risk of importation in Italy? }\end{array}$ & $1-3$ & $\begin{array}{l}1-\text { No/unknown } \\
2-\text { Possibly } \\
3-\text { Yes }\end{array}$ \\
\hline & \multicolumn{3}{|l|}{ International Reporting } \\
\hline 9 & $\begin{array}{l}\text { Is the event described possibly eligible, if validated, for notification } \\
\text { under EWRS or IHR? Does it refer to a disease targeted for } \\
\text { eradication? }\end{array}$ & $1-3$ & $\begin{array}{l}1-\text { No/unknown } \\
2-\text { Possibly } \\
3-\text { Yes }\end{array}$ \\
\hline \multirow[t]{2}{*}{10} & $\begin{array}{l}\text { Does the event describe an outbreak close to an } \\
\text { international border? }\end{array}$ & $1-3$ & $\begin{array}{l}1-\text { No/unknown } \\
2-\text { Possibly } \\
3-\text { Yes }\end{array}$ \\
\hline & Source of Information & & \\
\hline 11 & Is the report from a trusted source? & $1-4$ & $\begin{array}{l}1 \text { - Report from a potentially unreliable source } \\
2 \text { - Report from a potentially reliable source (eg, NGO, news } \\
\quad \text { sources of good reputation) } \\
3 \text { - Report from a reliable source (eg, WHO, national health } \\
\text { authorities) } \\
4 \text { - Validated event }\end{array}$ \\
\hline
\end{tabular}

${ }^{\mathrm{a}}$ This value was used when the event does not indicate a disease case or outbreak but a risk (eg, white powder incident). 
this tool using a similar methodology to the one described in the GHSAG EAR project ${ }^{25}$ through an analysis of historical news articles.

All the analysts assessed the articles independently and decided, in each case, whether the information was to be considered an event of the event-based surveillance and therefore sent to the regional focal points and, if so, whether it should be given a high or low priority. At the same time, the analysts scored each item using the tool, giving for each question a score that could vary from 1 to 3 . Based on this testing, we decided to design all questions of the tool with a scoring between 1 and 3 except for the questions on impact and source reliability, which could be scored between 1 and 4 , in order to give them a greater weight.

A team of 5 researchers, of whom 3 were analysts working in the IDEU-CNESPS, were in charge of the design and management of the national event-based surveillance system (EBS team). The 3 analysts had different professional backgrounds (1 infectious disease specialist, 1 statistician, and 1 biologist) and long-term experience in working in public health and infectious disease epidemiology. All had benefited from prior epidemic intelligence training. ${ }^{36}$

Following a presentation of the event-based surveillance development plan, elaborated in collaboration with the Italian Ministry of Health $(\mathrm{MoH})$ in April 2015, all 21
Italian regions agreed to appoint a regional focal point for event-based surveillance whose main duty was event verification and validation. The event-based surveillance contact points in the $\mathrm{MoH}$ included the Italian IHR national focal point and the Italian EWRS contact point.

The analysts screened each item captured by the preexisting MedISys disease categories in Italian, by the EXPO 2015 MedISys categories, as well as any item captured by our Google Alerts, once daily on an individual weekly rotation basis. Each day, the on-duty analyst assessed this content for nonexact duplication and relevance to the event-based surveillance objectives. On the basis of this assessment, using NewsDesk, the analyst composed a newsletter including all daily signals, classified according to the following disease groups: bacterial meningitis/sepsis, respiratory infections, foodborne illnesses, arboviral diseases, tuberculosis, other vaccine-preventable diseases, other zoonosis, potential intentional releases of biological agents, and other. This newsletter was sent to the event-based surveillance team and to the $\mathrm{MoH}$. The $\mathrm{MoH}$ also received an immediate email from the on-duty analyst if an event that could, even remotely, suggest a possible intentional release of a biological agent was detected.

The identified signals were shared each day among the event-based surveillance team. The researchers could use

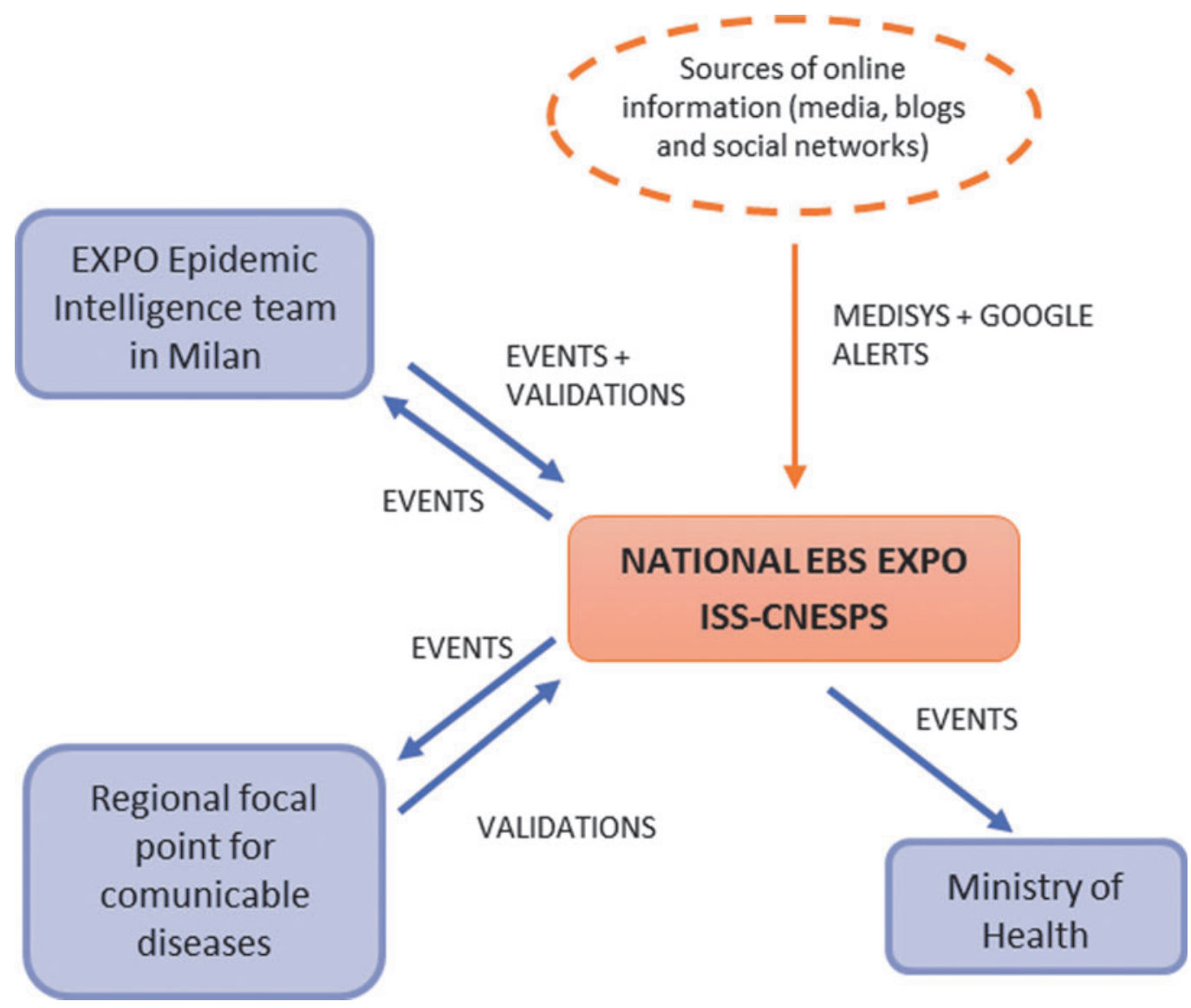

Figure 1. Information Flow Diagram 
the Italian EBS assessment tool, in a nonbinding way, to decide which signals should be considered events. As soon as the list of daily events was defined, an email describing what events were being monitored that day at the national level was sent to the EXPO epidemic intelligence team in Milan. Since May 2015, all events were then sent for validation to the Italian regional focal points, who also investigated any possible epidemiologic link to EXPO. The $\mathrm{MoH}$ was copied on all communications. Figure 1 provides a schematic representation of this information flow.

For the duration of the event-based surveillance, daily metrics on the number of items captured by the MedISys categories were collected. The daily number of Google alert items captured was manually compiled. Data on signals detected (from MedISys and Google Alerts), date, disease group, and source were automatically imported from the daily newsletter in a Microsoft Access database (Microsoft Corp, Redmond, WA). Information on classification of signals as events, the validation process, and its outcome were manually added to the records in the database.

The statistical analysis of the data was performed using STATA 12 (StataCorp LP, College Station, TX). We applied a linear regression model to the number of items filtered each day to verify if the data showed trends over time. We then analyzed the cyclical pattern of this data using moving averages and fitted a series of linear regression models with sine-cosine terms for periodic variation.

Table 2. List of Pathogens, Illnesses, and Syndromes Selected as Priorities for Event-Based Surveillance During EXPO 2015

\begin{tabular}{|c|c|c|c|}
\hline \multirow[b]{2}{*}{ Pathogen/Illness/Syndrome } & \multicolumn{3}{|c|}{ Assessment of the Risk in the Context of EXPO 2015 for: } \\
\hline & Importation & Transmission & Exportation \\
\hline Measles & Medium-High & Medium-High & Medium-High \\
\hline Food- and waterborne illnesses ${ }^{a}$ & Low & Medium-High & Medium-High \\
\hline West Nile virus disease & Low & Medium & Medium \\
\hline Legionella & Not applicable & Medium & Not applicable \\
\hline Other acute respiratory infections & Medium-Low & Medium-Low & Medium-Low \\
\hline Enterovirus D68 & Medium-Low & Medium-Low & Medium-Low \\
\hline Other infectious diseases with rash & Medium-Low & Medium-Low & Medium-Low \\
\hline Ebola virus disease (EVD) & Medium-Low & Very Low & Very Low \\
\hline Meningococcal disease & Low & Low & Low \\
\hline Influenza & Low & Low & Low \\
\hline Tuberculosis & Low & Low & Low \\
\hline Chikungunya & Low & Low & Low \\
\hline MERS Coronavirus & Low & Very Low & Very Low \\
\hline Poliomyelitis & Low & Very Low & Very Low \\
\hline Plague & Low & Very Low & Very Low \\
\hline Cholera & Low & Very Low & Very Low \\
\hline Dengue virus disease & Low & Very Low & Very Low \\
\hline Zika virus disease & Low & Very Low & Very Low \\
\hline Malaria & Low & Very Low & Very Low \\
\hline Marburg virus disease & Very Low & Very Low & Very Low \\
\hline Syphilis & Very Low & Very Low & Very Low \\
\hline Avian influenza & Not applicable & Very Low & Not applicable \\
\hline
\end{tabular}

Invasive group A Strep Infection; leptospirosis; anthrax; HIV infection; arenavirus infection; rabies; SARS virus infection; smallpox; diphtheria; pneumococcal disease, and pertussis were also included in the priority list of diseases on the basis of the assessment conducted ahead of the London Olympics 2012.

${ }^{a}$ Eight conditions were included under food- and waterborne illnesses: viral gastroenteritis, bacterial food intoxications, E. coli, Campylobacter, hepatitis A, Salmonella, Shigella, and other bacterial/viral food- and waterborne diseases. 
We applied a linear regression model to the number of signals and of events identified each week and performed a descriptive analysis of signals, events, and event-based surveillance priority events by disease group.

\section{RESUlts}

We included 40 infectious diseases and agents with potential for intentional release in our list of diseases, pathogens, and conditions (Table 2). We were unable to prioritize further given the nature of the EXPO 2015 gathering.

We classified the risk of: (1) importation, transmission, or exportation of measles and food- and waterborne infections as medium/high; (2) legionella and West Nile virus disease transmission as medium; and (3) active transmission of meningococcal meningitis in the EXPO 2015 venue and of introduction of chikungunya and Zika viruses as low.

All listed conditions were found to be already monitored by both statutory and enhanced indicator-based surveillance. We concluded that event-based surveillance could contribute to: (1) the monitoring of infectious diseases, and (2) the investigation of epidemiologic links between validated events and participation in EXPO 2015 in Milan.

\section{Event-Based Surveillance Monitoring}

From April 6 to November 30, 2015, 3 analysts monitored, assessed, and reported items filtered into the 206 MedISys disease threat-categories $(247,215$ in total), into 9 MedISys
EXPO 2015 categories (1,304 in total), and into 21 Google Alerts (19,546), with a total mean of 9,711 items per week (ranging from 2,700 to 15,000).

No statistically significant linear trend $(p=0.68)$ was found in the number of daily items filtered by MedISys and Google Alerts during the 8 months of surveillance. The items showed a daily and 4-monthly cyclical pattern, with a lower number of items during weekends and in the summer months (Figure 2).

We identified 470 signals (411 new signals and 59 follow-ups of previous signals). No statistically significant linear trend ( $p=0.98$ ) was found in the number of weekly signals during the 8 months of surveillance. The most frequently detected signals were classified in the following disease groups: foodborne illnesses $(21.5 \%)$, bacterial meningitis/ sepsis $(21.0 \%)$, and vectorborne diseases $(10 \%)$.

A total of 268 signals (57\%) were classified as events (Figure 3). No statistically significant linear trend ( $p=0.99)$ was found in the number of weekly events during the 8month surveillance period. Of the 21 Italian regions, 19 received at least 1 validation request and 16 validated at least once during the reporting period. Half of the events (135, $50 \%$ ) were validated, 129 were confirmed, and 6 were classified as hoaxes (PPV 95.6\%). We did not confirm any intentional release of biological agents nor did we find any epidemiologic link between the events detected and EXPO 2015.

We detected 122 event-based surveillance priority events, of which 36 had at least 1 validation. A validated meningococcal meningitis outbreak in one region in central Italy

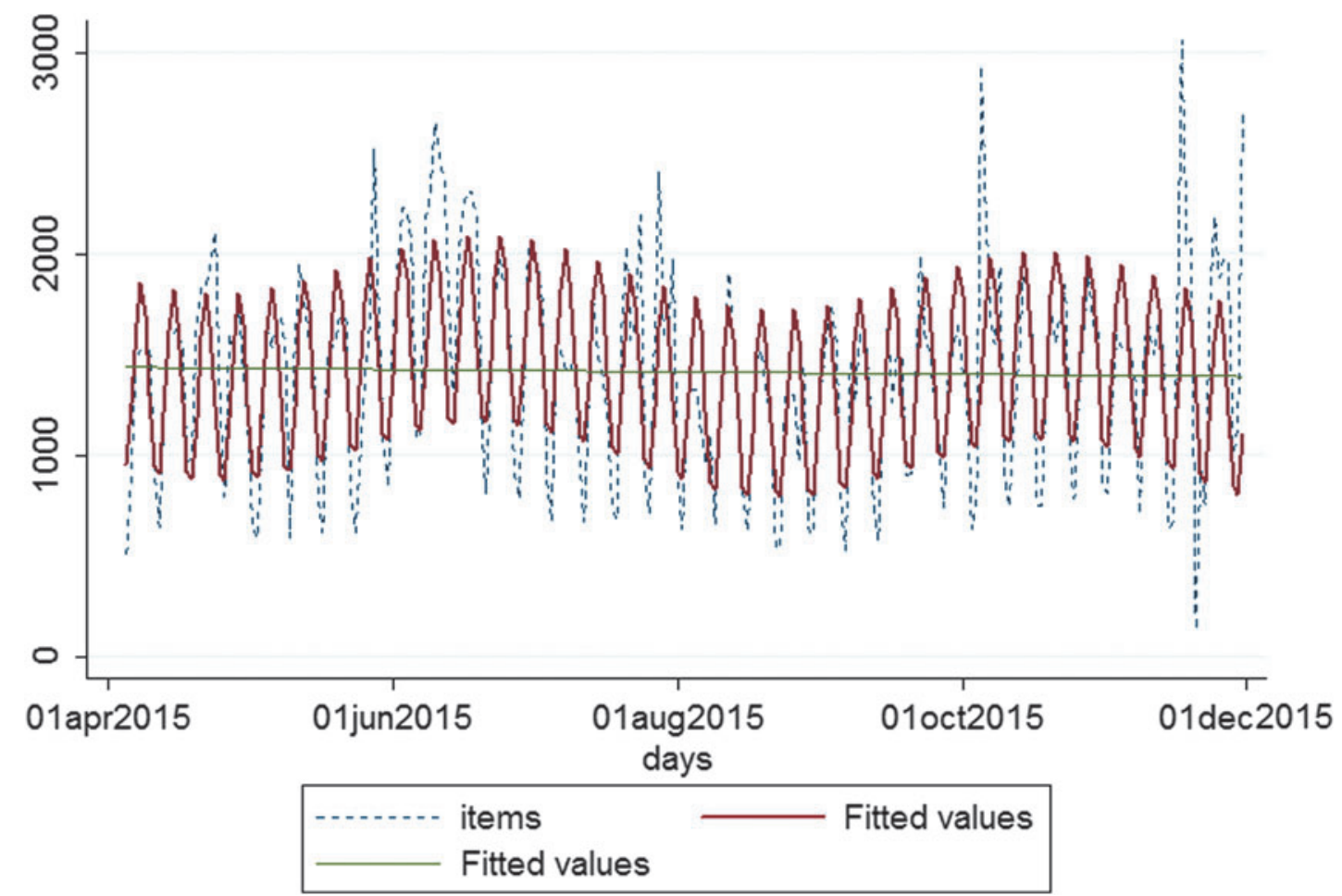

Figure 2. Trend and Cyclical Pattern of the Items Filtered Daily by MedISys and Google Alerts 
25

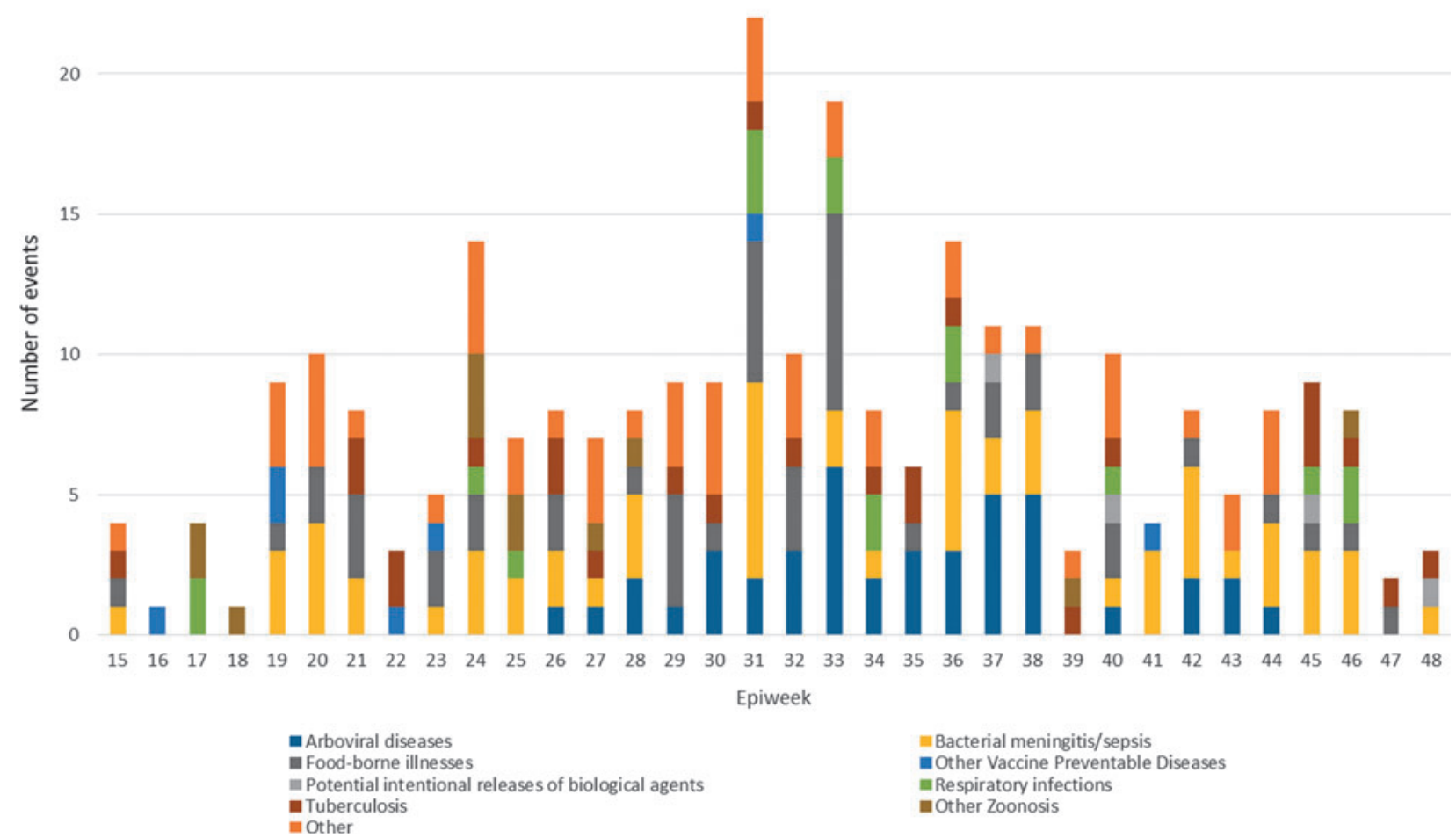

Figure 3. Number of Events Detected by Disease Group and Epiweek of Publication, April-November, 2015

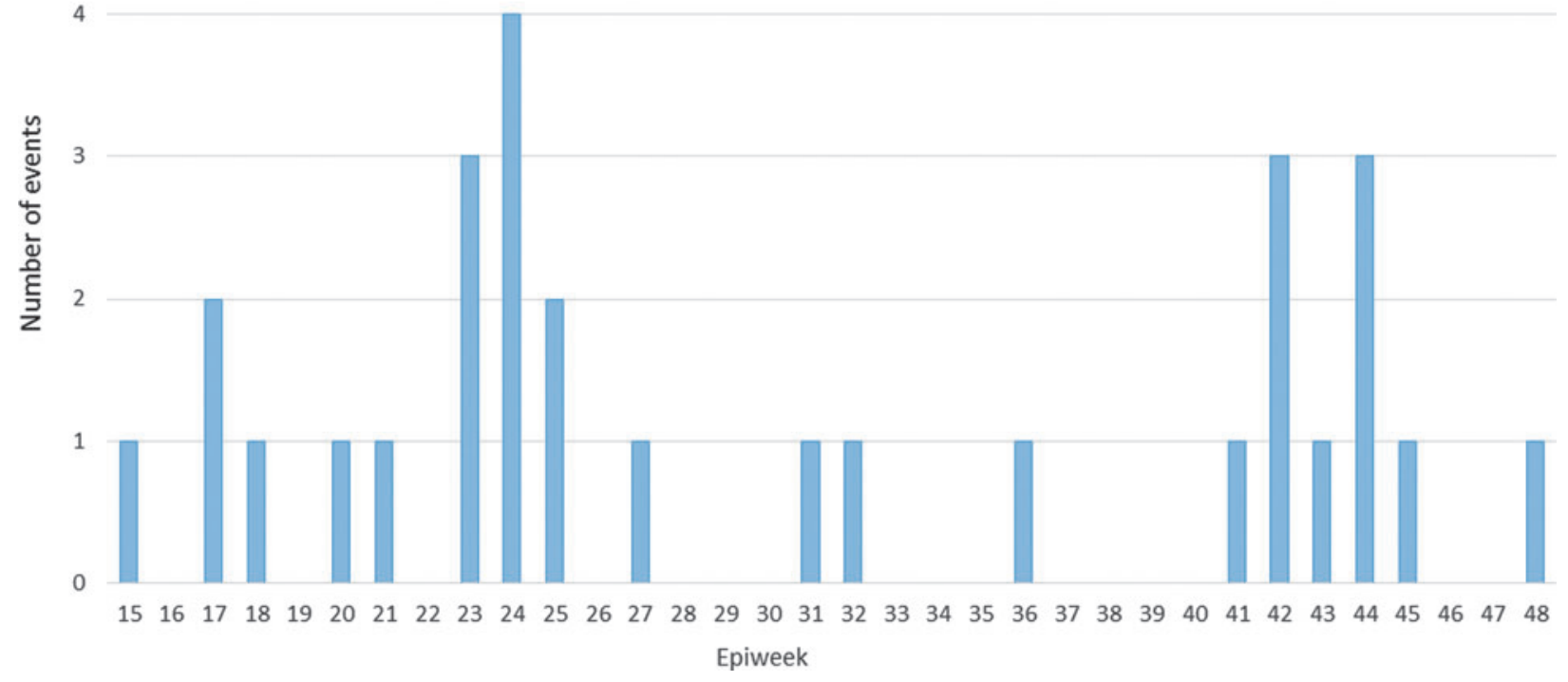

Figure 4. Events Linked to the EBS Priority Event Meningococcal Meningitis, April-November 2015 
was the most severe event-based surveillance priority event we detected (Figure 4). The most frequently detected priority events described human cases of foodborne illness ( 48 priority events) that occurred at different times in 15 different regions across the country and "other" events ( 40 priority events), mainly describing human cases of scabies occurring among newly arrived irregular migrants traveling via sea. We also observed 10 tuberculosis priority events occurring in 6 different regions across the country, 8 arboviral priority events due to sporadic imported dengue fever cases and sporadic cases of West Nile fever in northern Italy, and 1 respiratory priority event due to legionella infection.

\section{Discussion}

Conducting a risk assessment before implementing the national event-based surveillance system in Italy helped us in defining a list of conditions to include in the monitoring categories, taking into account the epidemiologic context and existing indicator-based surveillance systems. It also raised the analysts' awareness of the diseases, pathogens, and conditions for which there was higher risk, which made the assessments of signals easier during the surveillance period. Finally, the assessment process clearly linked the original mandate given by the Italian health authorities with the specific event-based surveillance objectives we defined.

The adaptation of the MedISys event-based surveillance platform to the EXPO event-based surveillance monitoring requirements through the update of the sources and the definition of ad hoc additional categories was feasible even considering the tight time constraints thanks to the flexibility of the system and the dedication of the JRC team. Our time series analysis showed that item detection was stable over time once we took into account daily and 4-monthly cyclical variations. This indicates that the event-based surveillance system combining MedISys and Google Alerts did not lose the capacity to detect items, which could be an issue to consider when using a platform with a predetermined source directory. We concluded that the constant integration of additional sources retrieved through Google Alerts is beneficial when using platforms of this type.

Even though the EXPO was protracted and took place during the summer period, and we had no dedicated staff, we were able to guarantee a fully operational rotation of analysts with no discontinuity. This achievement was largely because of the enthusiasm and dedication of the team. This was the first time event-based surveillance had been implemented in Italy with regional validation. The validation rate, although not yet optimal, is encouraging, reflecting the fact that event-based surveillance was well accepted by a large number of regions. This is particularly relevant considering that, because of the short deadlines for implementation, it was possible to conduct pre-EXPO event-based surveillance training sessions only in the Lombardia region.
Although naturally occurring outbreaks were detected by event-based surveillance in several Italian regions, we could not link any events captured by the event-based surveillance system to EXPO 2015. While an in-depth evaluation will be needed to define whether small outbreaks linked with EXPO 2015 were captured by indicator-based surveillance and not by event-based surveillance, no potential public health emergencies of international concern were linked to this gathering and no intentional releases of biological agents were reported to our knowledge.

It is easier to link outbreaks to mass gatherings, both at national and international levels, when they occur in a limited time and involve a specific population subgroup, as was the case of a recent outbreak of measles linked to a 2day dog show in Slovenia. ${ }^{14,37}$ Because of its global nature, protracted time scale, and unspecific target population, linking outbreaks to the EXPO 2015 was particularly difficult, which might have limited our detection capacity. However, the event-based surveillance introduced a new systematic request for regions to investigate links between infectious disease events across Italy and the EXPO.

The events we detected had a very high positive predictive value. We do not think that source bias alone can explain this behavior. Even though most sources we initially integrated in MedISys were media sites, official portals, and known reliable blogs, Google Alerts did not have any source filter and picked items from news as well as social media. These were then transmitted to MedIsys. Another possible explanation could be that responses to validation requests might have been sent more frequently when events were true. This aspect will need further investigation.

Epidemic intelligence is a relatively new discipline in public health $^{16,38}$ that incorporates event-based surveillance $39-41$ through internet-based biosurveillance systems. ${ }^{30,32,33,42-45}$ WHO, in article 9 of the IHR, ${ }^{46}$ recognized the use of other sources of information for early warning purposes, and more recently stated that event-based surveillance significantly increases the sensitivity of surveillance systems. ${ }^{16}$ Implementation of event-based surveillance at the global level is well-established in WHO, ECDC, and the US Centers for Disease Control and Prevention (CDC). ${ }^{47,48}$ While eventbased surveillance implementation during mass gatherings has been described, ${ }^{35,49,50}$ event-based surveillance integration is not common at the national level ${ }^{51}$ and has been recently recommended by WHO. ${ }^{47}$ As in previous massgathering experiences, ${ }^{49}$ the national Italian event-based surveillance system had a complementary role to existing indicator-based surveillance systems, acting as a safety net. Pending a formal evaluation of the event-based surveillance system, both in relation to the EXPO 2015 mass gathering and more generally to public health in Italy, the surveillance results suggest that the system was useful in providing additional realtime evidence that no health emergencies were occurring during EXPO. They also suggest that the system was effective in detecting ongoing outbreaks in Italy and promoting the systematic investigation of epidemiologic links with EXPO. 


\section{Conclusions}

We report the rationale and implementation of the first national event-based surveillance system set up for a mass gathering in Italy. In our view, this concrete example of event-based surveillance application in a national context is valuable in gaining experience with, and collecting evidence on, functioning eventbased surveillance procedures, processes, and tools.

Our experience suggests that while useful in confirming the absence of ongoing public health emergencies, the event-based surveillance system was not pivotal to surveillance in the EXPO 2015 context, where preexisting robust indicator-based surveillance systems were not only alerted but enhanced. However, our findings also suggest that event-based surveillance might be of use in early detection of infectious disease outbreaks in routine surveillance.

A more structured evaluation of the event-based surveillance system is needed to verify these hypotheses and evaluate the usefulness of the event-based surveillance system and its added value for mass gatherings and routine surveillance of infectious diseases.

\section{ACKNOWLedgments}

The rapid risk assessment and the event-based surveillance was possible thanks to the support and input of the following subject matter experts in the Infectious Disease Epidemiology Unit of the Italian Institute of Public Health (ISS): Maria Cristina Rota, Paolo D'Ancona, Antonino Bella, Antonietta Filia, Caterina Rizzo, Valeria Alfonsi, and Cristina Giambi; and to the support of Paolo D'Ancona, Silvia Declich, and Alicia Barrasa Blanco in their roles as EPIET supervisors and coordinator.

We thank all the Italian regions for supporting this initiative and the regional event-based surveillance focal points for their participation and validation of events. We gratefully acknowledge the Italian Ministry of Health for financially and technically supporting the establishment of the event-based surveillance system and its functioning during the EXPO mass gathering. JRC received funding from the European Centre for Disease Prevention and Control (ECDC) to further develop the MedISys system.

We would like to express our gratitude to Denis Coulombier, Kaja Kaasik Aaslav, Alistair Donachie, and all the ECDC event-based surveillance team at the Emergency Operations Centre and to Ray Arthur, Jason McKnight, and all the GHSAG EAR analysts' team, for including EXPO 2015 in their threat monitoring categories.

\section{Regional Focal Points, EBS SurVeIllance Work Group}

The following people served as regional focal points for event-based surveillance:
Vittorio De Micheli (Piemonte); Alessandra Piatti, Maria Gramegna (Lombardia); Mauro Ruffier, Gabriella Furfaro (Valle D'Aosta); Anna Maria Trenti (Provincia Autonoma di Trento); Bernhard Natter (Provincia Autonoma di Bolzano); Francesca Russo, Francesca Zanella (Veneto); Tolinda Gallo, Loris Zanier (Friuli Venezia Giulia); Roberto Carloni, Ilaria Cremonesi, Sergio Schiaffino (Liguria); Claudio Po, Maria Grazia Pascucci, Alba Carola Finarelli (Emilia Romagna); Emanuela Balocchini, Lucia Pecori (Toscana); Maria Donata Giaimo, Anna Tosti (Umbria); Daniela Cimini, Daniel Fiacchini, Giuliano Tagliavento (Marche); Fabrizio Perrelli, Amalia Vitagliano, Enrico Volpe (Lazio); Manuela Di Giacomo (Abruzzo); Pasquale Gino Iannaccone, Teodoro Campo (Molise); Renato Pizzuti (Campania); Rosa Prato, Maria Giovanna Cappelli, Domenico Martinelli (Puglia); Gabriella Cauzillo, Francesco Locuratolo, Maria Giovanna Trotta (Basilicata); Giacomino Brancati, Sandro Giuffrida, Anna Mignuoli, Lorenzo Surace (Calabria); Mario Palermo, Maria Antonietta Bullara, Salvatore Scondotto (Sicilia); Donatella Campus, Bruno Massidda, Gabriella Sirigu, Marcello Tidore, Anna Maria Vecchi, Rita Masala, Pierina Tanchis (Sardegna).

\section{REFERENCES}

1. World Health Organization. Communicable Disease Alert and Response for Mass Gatherings: Key Considerations. Geneva: World Health Organization; 2008. www.who.int/ csr/Mass_gatherings2.pdf. Accessed April 20, 2016.

2. EXPO Milano 2015. http://www.EXPO 2015.org. Accessed April 20, 2016.

3. Regione Lombardia. Expo, Sorte: la regione ha vinto la sfida della mobilità. http://www.regione.lombardia.it/cs/Satellite?c= News\&childpagename=Regione\%2FDetail\&cid=121376389 5410\&pagename=RGNWrapper. Accessed April 20, 2016.

4. Madeincongress.it. Turismo: la regione Lazio scommette sul nuovo portale "Visitlazio.com." http://www.madeincongress.it/ notizie-fiere-eventi/140509-4130-turismo-regione-lazio-visitlazio

5. EXPO Milano 2015. Offerte "Made of Italians." http:// www.EXPO 2015.org/archive/it/progetti/made-of-italians.html. Accessed April 20, 2016.

6. EXPO Milano 2015. Official global rail carrier. http:// www.fsitaliane.it/fsi/Impegno/Expo-Milano-2015/EXPOMilano-2015. Accessed April 20, 2016.

7. Ilvelino.it. Italo "scalda i motori" per l'Expo. http://www. ilvelino.it/it/article/2014/12/05/italo-scalda-i-motori-per-lexpo/ b9b46eb0-46be-4675-9b6b-140039bd3d91/. Accessed April 20, 2016.

8. Economopoulou A, Kinross P, Domanovic D, Coulombier D. Infectious diseases prioritisation for event-based surveillance at the European Union level for the 2012 Olympic and Paralympic Games. Euro Surveill 2014;19(15):pii. 20770.

9. Ehresmann KR, Hedberg CW, Grimm MB, Norton CA, MacDonald KL, Osterholm MT. An outbreak of measles at an international sporting event with airborne transmission in a domed stadium. J Infect Dis 1995 Mar;171(3):679683. 
10. Centers for Disease Control and Prevention (CDC). Risk for meningococcal disease associated with the Hajj 2001. MMWR Morb Mortal Wkly Rep 2001;50(6):97-98.

11. Karas JA, Nicol MP, Martinson N, Heubner R. An outbreak of food poisoning among children attending an international sports event in Johannesburg. S Afr Med J 2001 May;91(5):417-421.

12. Den Boer JW, Yzerman EP, Schellekens J, et al. A large outbreak of Legionnaires' disease at a flower show, the Netherlands, 1999. Emerg Infect Dis 2002;8(1):37-43.

13. Centers for Disease Control and Prevention (CDC). Multistate measles outbreak associated with an international youth sporting event-Pennsylvania, Michigan, and Texas, August-September 2007. MMWR Morb Mortal Wkly Rep 2008 Feb 22;57(7):169-173.

14. Grgič-Vitek M, Frelih T, Ucakar V, et al. An outbreak of measles associated with an international dog show in Slovenia, November 2014. Euro Surveill 2015;20(3):pii: 21012.

15. Botelho-Nevers E, Gautret P. Outbreaks associated to large open air festivals, including music festivals, 1980 to 2012. Euro Surveill 2013;18(11): 20426.

16. World Health Organization. Early Detection, Assessment and Response to Acute Public Health Events: Implementation of Early Warning and Response with a Focus on Event-Based Surveillance. Interim Version. Geneva: World Health Organization; 2014. http://apps.who.int/iris/bitstream/10665/ 112667/1/WHO_HSE_GCR_LYO_2014.4_eng.pdf. Accessed April 20, 2016.

17. EpiCentro. Syndromic surveillance system on access to emergency rooms [Italian]. http://www.epicentro.iss.it/focus/ sorveglianza/ProntoSoccorso.asp. Accessed April 20, 2016.

18. Istituto Superiore di Sanità. Syndromic surveillance system for seasonal influenza. InfluNET [Italian]. http://www.iss.it/ iflu/. Accessed April 20, 2016.

19. Napoli C, Riccardo F, Declich S, Dente MG, Pompa MG, Rizzo C, Rota MC, Bella A; National Working Group. An early warning system based on syndromic surveillance to detect potential health emergencies among migrants: results of a two-year experience in Italy. Int J Environ Res Public Health 2014 Aug 20;11(8):8529-8541.

20. Riccardo F, Napoli C, Bella A, et al. Syndromic surveillance of epidemic-prone diseases in response to an influx of migrants from North Africa to Italy, May to October 2011. Euro Surveill 2011;16(46):pii: 20016.

21. Epidemiological Consultation Team. Surveillance system in place for the 2006 Winter Olympic Games, Torino, Italy, 2006. Euro Surveill 2006;11(2):E060209.4.

22. Ansaldi F, Orsi A, Altomonte F, et al. Emergency department syndromic surveillance system for early detection of 5 syndromes: a pilot project in a reference teaching hospital in Genoa, Italy. J Prev Med Hyg 2008 Dec;49(4): 131-135.

23. Guasticchi G, Giorgi Rossi P, Lori G, et al. Syndromic surveillance: sensitivity and positive predictive value of the case definitions. Epidemiol Infect 2009 May;137(5):662-671.

24. Hartley DM, Nelson NP, Arthur RR, et al. An overview of internet biosurveillance. Clin Microbiol Infect 2013;19(11): 1006-1013.

25. Riccardo F, Shigematsu M, Chow C, et al. Interfacing a biosurveillance portal and an international network of institutional analysts to detect biological threats. Biosecur Bioterror 2014 Nov-Dec;12(6):325-336.
26. Riccardo F, Greco D, Dente MG, et al. EpiInt: building on national capacity to introduce Epidemic Intelligence in Italy. Presented at: European Scientific Conference on Applied Infectious Disease Epidemiology (ESCAIDE); Lisbon; November 11-13, 2010. http://ecdc.europa.eu/en/ESCAIDE/ Documents/ESCAIDE2010_abstract_book.pdf. Accessed April 20, 2016.

27. Welfare.regione.lombardia.it. Expo MI news. Sistema di sorveglianza integrata delle Malattie Infettive per EXPO. http://www.welfare.regione.lombardia.it//cs/Satellite?c= Redazionale_P\&childpagename=DG_Sanita $\% 2 F$ Detail\&cid= 1213748624196\&pagename=DG_SANWrapper. Accessed April 20, 2016.

28. European Centre for Disease Prevention and Control (ECDC). Communicable Disease Threats Report. http://ecdc.europa.eu/ en/publications/surveillance_reports/Communicable-DiseaseThreats-Report/Pages/cdtr.aspx. Accessed April 20, 2016.

29. Nuttall I. International Health Regulations (2005): taking stock. Bull World Health Organ 2014 May 1;92(5):310.

30. Linge JP, Verile M, Tanev H, et al, eds. Living in Surveillance Societies. Iaşi, Romania: Editura Universităţii Alexandru Ioan Cuza; 2012.

31. Linge JP, Steinberger R, Fuart F, et al. MedISys: Medical Information System. In: Asimakopoulou E, Bessis N, eds. Advanced ICTs for Disaster Management and Threat Detection: Collaborative and Distributed Frameworks. Hershey, PA: Information Science Reference; 2010:131-142.

32. Barboza P, Vaillant L, Mawudeku A, Nelson NP, Hartley DM, Madoff LC, Linge JP, Collier N, Brownstein JS, Yangarber R, Astagneau P; Early Alerting Reporting Project of the Global Health Security Initiative. Evaluation of epidemic intelligence systems integrated in the early alerting and reporting project for the detection of $\mathrm{A} / \mathrm{H} 5 \mathrm{~N} 1$ influenza events. PLoS One 2013;8(3):e57252.

33. Linge JP, Steinberger R, Weber TP, et al. Internet surveillance systems for early alerting of health threats. Euro Surveill 2009;14(13):pii:19162.

34. Linge JP, Mantero J, Fuart F, Belyaeva J, Atkinson M, van der Goot E. Tracking media reports on the Shiga toxin-producing Escherichia coli O104:H4 outbreak in Germany. In: Akan O, Cao J, Coulson G, et al, eds. Lecture Notes of the Institute for Computer Sciences, Social Informatics and Telecommunications Engineering. New York: Springer Verlag; 2012:178-185.

35. Mantero J, Szegedi E, Payne Hallström L, et al. Enhanced epidemic intelligence using a web-based screening system during the 2010 FIFA World Cup in South Africa. Euro Surveill 2014;19(18):pii: 20796.

36. EpiSouth Network. Training/Stage on Epidemic Intelligence at ISS, Rome 17-20 September 2013. http://www. episouthnetwork.org/content/trainingstage-epidemic-intelligenceiss-rome-17-20-september-2013. Accessed April 20, 2016.

37. Filia A, Riccardo F, Del Manso M, D’Agaro P, Magurano F, Bella A; Regional contact points for measles surveillance. Letter to the editor: Measles outbreak linked to an international dog show in Slovenia-primary cases and chains of transmission identified in Italy, November to December 2014. Euro Surveill 2015;20(9):pii: 21050.

38. Paquet C, Coulombier D, Kaiser R, Ciotti M. Epidemic intelligence: a new framework for strengthening disease surveillance in Europe. Euro Surveill 2006;11(12):212214 . 
39. Heymann DL, Rodier GR; WHO Operational Support Team to the Global Outbreak Alert and Response Network. Hot spots in a wired world: WHO surveillance of emerging and re-emerging infectious diseases. Lancet Infect Dis 2001; 1(5):345-353

40. Lober WB, Karras BT, Wagner MM, et al. Roundtable on bioterrorism detection: information system-based surveillance. J Am Med Inform Assoc 2002;9(2):105-115.

41. Hartley D, Nelson N, Walters R, et al. Landscape of international event-based biosurveillance. Emerg Health Threats J 2010;3:e3.

42. Madoff LC. ProMED-mail: an early warning system for emerging diseases. Clin Infect Dis 2004;39(2):227-232.

43. Collier N, Doan S, Kawazoe A, et al. BioCaster: detecting public health rumors with a web-based text mining system. Bioinformatics 2008;24(24):2940-2941.

44. Keller M, Blench $\mathrm{M}$, Tolentino $\mathrm{H}$, et al. Use of unstructured event-based reports for global infectious disease surveillance. Emerg Infect Dis 2009;15(5):689-695.

45. Brownstein JS, Freifeld CC. HealthMap: the development of automated real-time internet surveillance for epidemic intelligence. Euro Surveill 2007;12:E071129.

46. World Health Organization. International Health Regulations (2005). 2d ed. Geneva: World Health Organization; 2008. http://www.who.int/ihr/publications/9789241596664/en/. Accessed April 20, 2016.

47. World Health Organization. Technical Consultation on Event-Based Surveillance. Meeting Report. Lyon 19-21 March, 2013. Geneva: World Health Organization; 2013. http:// www.episouthnetwork.org/sites/default/files/meeting_report_ ebs_march_2013_final.pdf. Accessed April 20, 2016.
48. Hartley DM. Using social media and internet data for public health surveillance: the importance of talking. Milbank $Q$ 2014;92(1):34-39.

49. Severi E, Kitching A, Crook PD. Evaluation of the health protection event-based surveillance for the London 2012 Olympic and Paralympic games. Euro Surveill 2014;19(24): pii: 20832.

50. Yom-Tov E, Borsa D, Cox IJ, McKendry RA. Detecting disease outbreaks in mass gatherings using internet data. $J$ Med Internet Res 2014;16(6):e154.

51. Velasco E, Agheneza T, Denecke K, Kirchner G, Eckmanns $T$. Social media and internet-based data in global systems for public health surveillance: a systematic review. Milbank $Q$ 2014;92(1):7-33.

Manuscript received December 30, 2015;

accepted for publication March 31, 2016.

Address correspondence to: Flavia Riccardo, MD, PhD Researcher Communicable Disease Epidemiology Unit National Centre for Epidemiology, Surveillance and Health Promotion Istituto Superiore di Sanità Rome, Italy

E-mail: flavia.riccardo@iss.it 